\title{
The Important of Babies' Movement in the First Year of Life
}

\author{
Ph.D. Candidate. Sulltana Bilbilaj \\ "Pedagogical Academy Of Tirana", Tirana, Albania \\ tanabilbili@yahoo.com
}

\section{Doi:10.5901/jesr.2014.v4n3p381}

\begin{abstract}
Mother is the closest person and the one who has the greatest affinity to her child, so she must have information on the movement in order to be successful during the growing-up and development phase of the child. On birth a baby does not possess control on their willing movements. The child responses the environment stimulus via the primitive reflexes, which are stereotype and automatic movements. When in the womb, the movements of in the primitive reflexes help the brain development. After birth reflexes are survived in order to see the baby's neurological function. They also offer a great deal of opportunities on various aspects of the later functionality. Their presence or their absence is a crucial factor in different phases to set the foundation for the later development. These primitive reflexes must be stopped slowly during the first year of life and for this the movements are ferial must or condition. Every movement is a motored sensory happening linked with the understanding of our physical word, from where the new information generates. During the six-twelve first months of life the baby starts to grow up and mature, so does even the central nervous system. The primitive reflexes are starting to be replaced by more sophisticated regions of the brain. This happens when the survival system model is stopped, and in order to enhance better models of responses, the postural reflexes must be developed instead. Hen postural reflexes replays the primitive reflexes, the baby starts to take control over their body movements. The most of the babies gain immediately the primitive reflexes the first months of their life, thus setting the foundation for their later willing movement. Some children fail to gain full control during the first year of life and continue to grow in reflexive, where some primitive reflexes remain present and postural reflexes are not fully developed. When reflexes continue as in infancy, they interfere with development and can affect movement, visual skills, learning, and emotional well-being.
\end{abstract}

Keywords: movements, initial reflexes, postural reflexes, infancy, neurological development

\section{"Our mental and physical development is depended on our movements" Maria Montessori}

\section{Introduction}

The Increasing number of children with learning disorders, $15-20 \%$, is a nationwide problem that requires solution. One of the hypotheses put forward, the factors that affect this disorder, is not retardment of primitive reflexes, within their biological age of the first year of life. Since the primitive reflexes belong to the early age of the baby, the first year of life, and the lack of the theoretical and practical information for mothers, for the types of primitive reflexes, makes it to be an unknown topic, and not estimated by the Albanian medicine. Greater industrialization and modernization of society's everyday life, has led to the avoidance of movements, which are a necessity for this process. This study takes the analysis in children with learning disorders, who are tested for the preservation of primitive reflexes.

This phenomenon is worthy of studying for three reasons:

First, because of the nature of its effects. Movements are vital to prevent retardement of primitive reflexes, within their first biological year of life.

Second, because of the relationships that characterizes this phenomenon. The phenomenon is observed that shows double relationship, even as a product of factors, and as influencing factor. As a factor product, this phenomenon is observed because reflects the concerns and movements, balance, concentration as a factor of influencing the phenomenon, influences on children in physical and cognitive development.

Third, because of the importance of this phenomenon for the normal development of children. Even the fact that the reflexes are present or not in significant periods, also determine whether a child is characterized by normal or problematic development.

The impulses based on this study are of two natures: 1) theoretical and 2) practical. From a theoretical point of view, this study wants to analyze the relationship between the dependent variable, children and independent variable, 
moving therapy and want to emphasize three main things.

- First, how important is this relationship, viz how important is the independent variable, exercises for the dependent variable, children and the variety that accompanies it.

- Second, what is the character of the relationship, viz to see if this relationship is characterized by a positive or negative report.

- Third, what are the conditions that determine the character of the relationship. Viz, the study is interested to see in what circumstances the relationship appears positive and negative as well, and in what circumstances it occurs.

The impulses from a practical point of view are two:

- First, the negative/positive effects that accompany the presence, action, influence (or their lack) of the independent variable (movement) on the dependent variable (to children).

- Second, the need to identify the conditions in which the negative effects of independent variables on the dependent variable (children) can be eliminated.

Based on the facts that are observed in the daily life, regarding the children with cognitive disorders, the main question that this paper analyzes and tries to give an answer is:

Do the movements have any effect to unconstrained primitive reflexes, even they are beyond their biological age? The objectives and the hypotheses of the research, related to theories of unconstrained initial reflexes.

Study shows the phenomenon to children 6-10 years old age group, which are situated in the city of Vlora. It attempts to verify three realities.

- First, if observed, or not, the presence of initial reflexes is present;

- Second, if observed that is present, in what level is observed? Viz, if the level of preservation of unconstrained primitive reflexes that observed is high or low.

- Third, if changes are observed or not, when triggered independent variables, viz how children change when they undergo a motor therapy.

This phenomenon is studied from two perspectives: One is psychological perspective. (From this perspective, the study try to identify the characteristics and dynamics that characterize the dependent variable, children with learning disorders), and the other one is therapeutic perspective. (From this perspective, the study aims to see whether the application of some reflexive motor therapy techniques, manages to cause changes in the dependent variable).

This study considers the phenomenon of children with learning disorders associated with movements (independent variables):

The aim of this study is to look at what way and to what extent such factors can influence and effect changes in the level and trends related to the abnormalities observed in children with disorders. In this sense causality which this study puts at the spotlight, is the relationship between children with disorders (dependent variable) and reflexive movements (independent variables).

Regarding the phenomenon, researchers agree that there is a connection between the unconstrained initial reflexes and disturbances in learning.

This study uses the experimental method. The method puts the focus on the analysis of children aged 6-10 years old, children are selected from schools in Vlora, with joint disorders in learning.

The Analyzing of the dynamics is realized in experimental conditions in which we compare the features before and after putting into motion the independent variable, which sends messages to all stakeholders, but especially for mothers.

\section{Literature Review}

In this scientific article is addressed the degree of impact of movements in children with learning problems, where children will be exercised with reflexes, if they have such ones. Increasing the number of children with learning difficulties is a nationwide problem that requires immediate attention from neurobiology sciences, psychology, pedagogy, medicine etc. Difficulty in learning from the initial presence of reflexes, Babinski, Moro and Startle, walking or steps (Stepping), Research (Rooting), Gain (Sucking), Asymmetric tonic neck reflex (ATNR), Tonic reflex Maze (TLR), Palm reflex (Handheld), Plantar reflex (Plantar) Reflex Galant, parachute reflex of about 70 such is a neurological disorder, where children may have difficulty in speaking, reading, writing, spelling, reasoning, perception, memory, organization or information processing.

Primitive reflexes are essential for the survival and development in the womb, and in the first months of life (Hannanaford 1995). The time of appearance of initial reflexes phase, begin in the prenatal child in utero, where the first 
difficulty of the performance of early reflexes is very big. This fact makes it difficult to avoid interference disorders. Some initial reflexes are present at birth and are the indicators of neurobiological development, especially the brain, who is checked by a doctor (Wolf \& Binet. 1973). All the initial reflexes are active only within the first year of life, and parents lack of information about their role, and characteristics to monitor and help to act in due time. Signs of malfunctioning of the initial reflexes can be observed during this period, but the effects on learning disorders, especially come later, after the second year of life with the performance of language learning, learning in the pre-school years, and at school later.

The anatomical and biological initial reflexes, stay for a short period of time and under the influence of specific movements, based on the type of initial reflex, they constrain and leave the place to postural reflexes. This happens on stage when they are integrated with higher centers of the brain control (Zafeiriou, 2004). If they are retained beyond their normal age of integration, they can disturb some or all functions of the higher brain centers, which includes behavior, learning, integration of large or fine movements, and more neurological disorders (Salkind, 2002). Retained primitive reflexes are also a big problem that disrupts the structural foundations, emotional and biochemical and behavioral learning.

Neuroscientist and education researchers have discussions on extensive research and have issued separate arguments, about the learning process, referring to the study of the brain (Whitebread and Coltman 2008). Referring to the very early brain development in utero, it is affected by initial movements and reflexes (Rohkamm 2004; Melillo, 2009). Movements form the neural network models and approaches that make prevention and not allowing the connection of different brain areas, which are very important for the further stages of learning, communication, emotion, motivation (Frank A. \& Peter L, 1994). What happened to the brain during pregnancy if the child does not carry these reflexes at birth? Do initial movements and reflexes operating in the pre-natal period? Cognitive and physical development of the baby is at risk. What happened to the original reflexes, which are present beyond their biological age, the first year of life of the baby? They should be replaced with postural reflexes to provide a form of practice that later harmonized in voluntary movement (Rohkamm 2004). Movements functioning and what happened to the brain even at the stage it is not done replacing reflexes? Initial learning comes through our sensibility. Any initial reflex is associated with one or more of the sensory processing systems: space, taste, touch, smell, sight, hearing, pro perceptive and / or interceptive (Melillo, 2009). Therefore, if the initial reflex is stored, the children may experience a malfunctioning in one or more of sensory processing systems. This can lead to what is known as a disorder of the sensory process which plays the main role in the learning process.

For the constraint of initial reflexes, is used a program based on the theory of repetition, viz, allow the repetition of the individual stages of development through repetition of movements that is based on early brain development (Goddard, 2002). The brain is given a "second chance" to pass through stages which lacked or were incomplete in the first part of the life, thus creating and developing nervous joint. Each reflex functions equipped with its own specific movements which have performance based on neurobiological function. Exercise with specific movements for each type of reflex, for example, Moro movement intimidation, is exercised by opening and closing of the limbs and the move of head as well, and these movements are exercised for a period of time until to make Moro fully constrained. ATNR through movements of the head and limbs with a clearly defined working on to help left right hemispheres to provide initial position with hands together placed on knees and feet crossed in a position to sit somewhere, eg in chair, The first step is to turn your head to the left, escort the head with the left hand opening, then right hand, left foot, right foot. Returning to the same place on the initial position of the legs in the beginning, the hands and in the bottom of the head so is dealt with the right side. A hyperactive hand and foot walk, make like floating in the air, a disleksic turn left and right, with wings outstretched, with his fist and thumb raised high to accompany the hand and eye movement with Focus on great finger, etc. The totality of movements leading to brain balancing programs with a daily series of exercises selected sensory, physical, and academic (Melillo, 2009). Once abnormal reflex exercises are conducted, more academic problems, emotional and physical child postural reflexes disappear and busy place (Vasta. R Haith. M and Miller. S, 2004).

\section{As a Direct Movements Infant Cognitive Development?}

To understand the basics of this relationship opinion - motion, we must remember the early development of the human brain (Vasta, Haith and Miller). Baby undergoes a supernatural work of resistance and coordination, so that it passes from a state immobilization, staying lying on the move, in the first years of life. This act is associated only with massive processing of certain neural networks and learned through practice each new movement repertoire of movements. As the child grows, any development deploys sensory apparatus, especially the ears, mouth, hands, nose and eyes in a handy 
place for environmental data. Vestibular system is associated with abdominal and core muscles and back muscles are those who work for the establishment of the first head - a great achievement. While strengthening the back muscles, the child is able to raise his head to listen with both ears, and begin to see the world with both eyes. Sitting vertically on the back or front of the hands of the mother, as well as staying lying on the ground allows the child to work actively to strengthen the neck muscles.

Based on the above information on muscles, we conclude that the consequences of the frequent use of benches holder serving as child car seats, baby hold at an angle of 45 degrees, which Pego active muscular movements of the muscles of the neck or base. Although the child's eyes look forward movement is impeded and this causes the child is not active in the development of sight.

Child explores the feet and hands with his mouth through the game and it helps in enhancing and strengthening muscles. Eyes help the child in the first attempt to make rounds while pursuing an object and uses eye muscles to move the central part of the body. Then the main muscles come into play after the child strengthens the area around the shoulder, raising the shoulders and head in response to impetus sensors.

While the main muscle neural networks are developed and added mielina use, the child is able to stand against gravity and drag. With practice, initially a part of the body and then the other, the child moves from position to crawl down. Again, it depends on many of the key muscle activism shoulders and pelvis to work together. (Stiller \& Renate 1992).

We know for years that children who lacked vital essential phase of crawling can display later learning problems and concentration. The crawling, a cross lateral movement, activates neural development road between two large hemispheres of the brain. This allows both parts of the upper and lower body to work together, including the hands, feet, eyes (binocular vision) and ears (binaural hearing). To get equal stimulation, these senses use more environmentally and both sides of the body can move in a more integrated way for a more efficient operation.

Referring to the importance of crawling, walking to crawl or walk the cat in infancy have a clear orientation to the importance of movements in the learning process in the future, especially in the development of sight reading. Finally, with this entire development engine, the child learns resists gravity and maintain balance to walk and then to run. Children of coordinated stand, walk and run, or maintain balance with fast and accurate also present a splendid view of the intelligence and beauty of natural movements.

In the learning process is essential to infants or children are allowed to explore every aspect of the environment movement and balance, whether walking on the edge of the road, climb the tree or jump on mobile jet. Most mothers today, in modern times where industrialization life comes and progresses comforts, avoiding movements that children also can bring any risk to them. However with current perceptions, that the world is a dangerous place for children, they have not allowed their babies or children to move without limit where and when they want and how they want. Without having the opportunity to go do what I want to explore, their children have turned on the TV in their favorite passage. It is agreed that these children have had difficulty movement and balance as well as learning difficulties, especially in reading and writing that are faced in school. From a careful look at thirteen different brain studies, which found that exercise stimulates the growth and development of the brain and prevent brain aging. (Olsen and Eric, 1994, pp.33 - 35).

Recent studies are helping to explain how the movement is benefitted directly to the nervous system. Muscle activities, particularly coordinated movements seem to stimulate production of neurotrofine, natural substance that stimulates the growth of nerve cells and increases the number of neural connections in the brain. Studies in animals confirm this is about. A study at the University of California, Carl Cotman found that mice who ran on their exercise wheels had more than rats sendentar neurotrofin .

\section{Movement and Visual}

When a child explores his environment, eyes and eye muscles are in constant motion. Our sense of sight works more effectively when our eyes move actively taking sensory information from the environment. When our eyes stop moving, they do not receive sensory information and processing of information as the process occurs only within the brain. In a situation of active learning external muscles of the eye gaze constantly up and down, from side to side and around . Internal eye muscles reduce or expand the apple of the eye for proper light and the lens lashes muscles or extended or renewed on or near sight to look for away.

When moving the head and body, activate the vestibular system and strengthen eye muscles while moving the response. The more you move, the more the eyes of their muscles work together. Cooperation between the eyes enables children to focus, follow or focus on reading. While strengthen eye muscles and move more coordinated with 
each other, the brain developed and are available most relevant (Paul E. \& Gail E. 1990). This is because $80 \%$ of the muscle nerve terminals are connected directly through pro perception and the vestibular system, the motor nerve of the eye. (Gail E. 1995).

Often observed that children who have difficulty reading also experience difficulty when asked to focus on the thumb of the hand while moving it across their visual field. Their eyes jump, they complain that it causes pain and have difficulty concentrating were. This visual stress, when the eyes are not focused or not effectively coordinated, comes as a result of insufficient development of the eye muscle, often caused by lack of movement.

Infants begin by following the movements of the hands or feet of their eyes. With time, place and specific neural networks so developed hand- eye coordination. The baby is able to bring into view artifacts from the world to observe and learn. Coordinated hand / eye, foot / eye allows them to accurately objects in their environment. With practice and maturity of networking and coordination occurs a changeup / eye develops. Now leads the eye movements of the hand so that the totality of knowledge becomes the model for internal motion. We can now learn to associate the movement with Amy viewing as described in Chapter 1, made with respect of football. This is essential to write, draw, to decline an instrument in learning a sport or a dance.

Eye muscles also play an important role in classroom learning. Before entering school, and three -dimensional peripheral eyesight enables learning environment. They integrate with kinesthetics viewing to understand format, the movement of natural forms and the awareness space. When children enter school, they are often expected to develop their focus foeval two dimensional tasks. Foeval focus in school is important to see small letters, two dimensional static on a page . The transition from three dimensional focus and spun periphery foeval focus is immediate and in many cases unnatural.

Emotionally stressful situations, as a sense of instinctive response to danger, the eyes move peripherally, so they may perceive as much as possible from the environment. This makes it very difficult for the eyes to work together and to observe.

When people live in constant stressful circumstances, external eye muscles tend to be strengthened by extending the internal muscles of the eye and making foeval and observing focusing more difficult. To children with learning difficulties, especially the autistic and those eyes are always disleksic a significant factor. The fact of the movement of the finger before and after the eye causing pain and discomfort. It is not surprising that these children have problems to read and not read. Their muscles ache and must be retrained before they read in order to remain calm. We should note the information on brain gymnastics, which presents a simple way to activate all the muscles of the eye. Exercises reduce the stress response and help to read and easily understood.

Mobility is an integral part of all mental process, atomic movement that causes molecular movement, which causes the cell (electric), to think and to make clear the action.

\section{Research Methodology}

It is a qualitative study, phenomenological, where required to further deepen the knowledge on the role of the movements of the baby in the first year of life. For the realization of the study with two groups of children, and the control experiment was conducted two assessments on the level of preservation of primitive reflexes, before and after the experiment. Evaluations were carried out under the support of studying neuropediater mothers and in the presence of children. The first assessment was conducted during September 2012 and the Second Assessment was conducted in June 2013. All children were tested for the presence of unconstrained initial reflexes Moro, Research (Rooting), Gain (Sucking), Asymmetric tonic neck reflex (ATNR), Symmetric tonic neck reflex (STNR), Tonic Labyrinth reflex (TLR), reflex palm (Handheld) , Reflex Galant.

Testing for maintaining the level of initial reflexes became INPP method (S. Goddard reflexes, learning, and behavior. Did window into a child's mind. Eugene, OR: FernRidge Press, 2005). These tests were modified by Attention, Balance and Coordination: the ABC's of learning success' by Sally Goddard Blythe (2009) and 'primitive Reflex Training, Visual Dynamix by Lori Moybray (2010) - a major source of primitive reflexes corrective exercises.

The result of tests throughout the procedure was based on standardized scales of 0-4 (Capute et al. 1984).

Based on the results of testing for unconstrained initial reflexes to get all children in the study, they were divided into two groups, group I and group control of the experiment. Children assigned to experiment reflexive motor underwent therapy for 9 months October 2012 to June 2013, to assess whether the interference with motor therapy will affect the initial integration of reflexes that are stored beyond their biological age. Therapy was conducted twice a day by 10-15 minutes at the beginning of the experiment up to 45 minutes at the end of the experiment. The exercises were obtained 
from individual INPP program involving the use of models early movements performed by children in the first year life.

Parents of all participants gave informed written consent and the study was approved by the Council of Professors of the European University of Tirana.

\section{Purpose}

Tested with children aged 6-10 years old, with learning disorders (neurological) because of initial storage reflexes, if repeating the same patterns as reflexive movements of the first year of life, will positively affect their containment and consequently will have improved neuro - motor skills, and increase academic performance of school children.

\section{Sampling}

The sample was selected through a selective approach, taking a representative sample not casual. We study 14 children (6-10 year olds, 12 boys and 2 girls) diagnosed by a doctor with ADHD, autism, dyslexia, language disorders and have difficulty in learning These children were divided into two groups, the experiment group with 7 children, (6 boys and 1 girl) and control group with 7 children (6 boys and 1 girl). All children in the study were taken from the city of Vlora from different schools 9 - year public and private. Public schools "Lef Sallata", "Muco Delo", "Ismail Qemali", "Ibrahim Kushta" non-public schools "Kampionët" and "RealD". Permission to undergo the experiment, the children were taken from parents and from Directorate for Education Vlora.

\section{Hypothesis 1}

Children with learning disorders in age from 6 to 10 years old, have a high level of conservation unconstrained primitive reflexes.

\section{Hypothesis 2}

The level of preservation of primitive reflexes, decrease unconstrained when they undergo therapy reflexive motor, for a period of 9 months.

\section{The Study Findings}

Measurement of primitive reflexes before the experiment for all children in the study received a positive result that shows deviation over 0 .

\begin{tabular}{|l|c|c|}
\hline Unconstrained initial reflexes & Total & $\%$ \\
\hline Asymmetrical Tonic Neck Reflex (ATNR) & $14 / 14$ & $100 \%$ \\
\hline Tonic Labyrinthine Reflex (TLR) & $14 / 14$ & $100 \%$ \\
\hline Symmetrical Tonic Neck Reflex (STNR) & $9 / 14$ & $64 \%$ \\
\hline Spinal Galant Reflex & $6 / 14$ & $42 \%$ \\
\hline Moro Reflex & $11 / 14$ & $78 \%$ \\
\hline Rooting Reflex & $4 / 14$ & $28 \%$ \\
\hline Sucking Reflex & $2 / 14$ & $14 \%$ \\
\hline Palmar Reflex & $5 / 14$ & $35 \%$ \\
\hline
\end{tabular}

Of the 14 children in the study received 14 , or $100 \%$ of their guarding reflex ATNR and TLR, 9 children and $64 \%$ of them STNR guarding reflex, 6 children and $42 \%$ of them watched Spinal Galant reflex, 11 or $78 \%$ of them watched the Moro reflex, 4 or $28 \%$ of them watched Rooting reflex, 2 or $14 \%$ guarding reflex Sucking and 5 or $35 \%$ guarding Palmar reflex. 


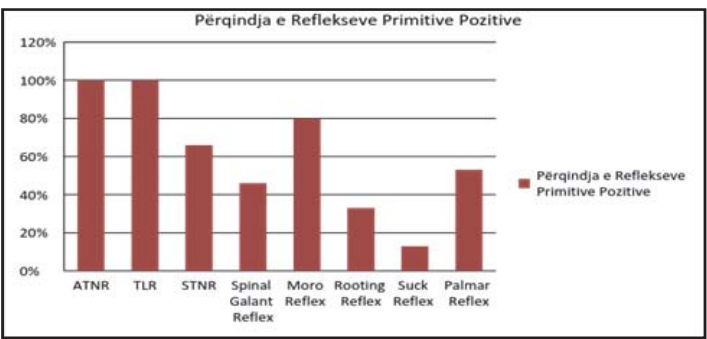

Measuring reflexes before the experiment only for children of the group to experiment

\begin{tabular}{|l|c|c|}
\hline Unconstrained initial reflexes & Total & $\%$ \\
\hline Asymmetrical Tonic Neck Reflex (ATNR) & $7 / 7$ & $100 \%$ \\
\hline Tonic Labyrinthine Reflex (TLR) & $7 / 7$ & $100 \%$ \\
\hline Symmetrical Tonic Neck Reflex (STNR) & $4 / 7$ & $57 \%$ \\
\hline Spinal Galant Reflex & $3 / 7$ & $42 \%$ \\
\hline Moro Reflex & $6 / 7$ & $85 \%$ \\
\hline Rooting Reflex & $2 / 7$ & $28 \%$ \\
\hline Sucking Reflex & $1 / 7$ & $14 \%$ \\
\hline Palmar Reflex & $3 / 7$ & $42 \%$ \\
\hline
\end{tabular}

7 children who are subject INPP Programme, 7 or $100 \%$ of them guarding reflex ATNR and TLR, four children or $57 \%$ of them guarding reflex STNR, 3 children and $42 \%$ of them watched Spinal Galant reflex, 6 or $85 \%$ of their guarding reflex Moro, 2, or $28 \%$ of them watched Rooting reflex, 1 or $14 \%$ guarding reflex Sucking and 3 or $42 \%$ guarding Palmar reflex.

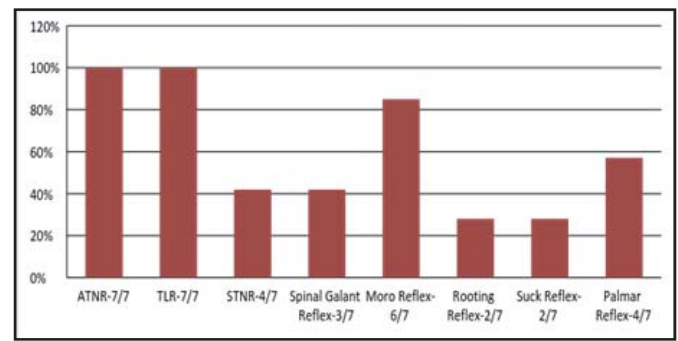

Measuring reflexes before the experiment only for children of the control group.

\begin{tabular}{|l|c|c|}
\hline Unconstrained initial reflexes & Total & $\%$ \\
\hline Asymmetrical Tonic Neck Reflex (ATNR) & $7 / 7$ & $100 \%$ \\
\hline Tonic Labyrinthine Reflex (TLR) & $7 / 7$ & $100 \%$ \\
\hline Symmetrical Tonic Neck Reflex (STNR) & $5 / 7$ & $64 \%$ \\
\hline Spinal Galant Reflex & $3 / 7$ & $42 \%$ \\
\hline Moro Reflex & $5 / 7$ & $78 \%$ \\
\hline Rooting Reflex & $2 / 7$ & $28 \%$ \\
\hline Sucking Reflex & $1 / 7$ & $14 \%$ \\
\hline Palmar Reflex & $2 / 7$ & $35 \%$ \\
\hline
\end{tabular}

7 children control group who did not undergo INPP Program, 7 or $100 \%$ of their guarding reflex ATNR, and TLR, 5 or $64 \%$ of them children watched STNR reflex, 3 children and $42 \%$ of them watched Spinal Galant reflex, or $78 \%$ of them watched the Moro reflex, 2 or $28 \%$ of them watched Rooting reflex, 1 or $14 \%$ guarding reflex Sucking and 2 or $28 \%$ guarding Palmar reflex. 


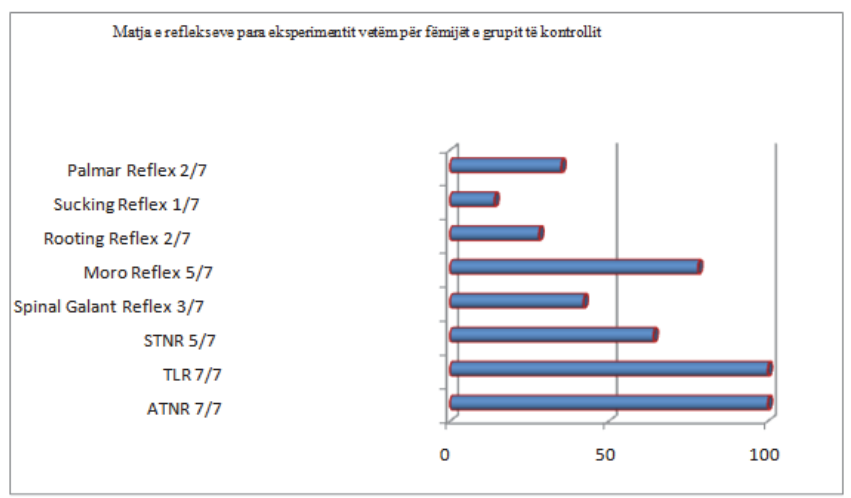

Reflexes measurements after the experiment: the experiment group

\begin{tabular}{|l|c|c|}
\hline Unconstrained initial reflexes & Total & $\%$ \\
\hline Asymmetrical Tonic Neck Reflex Reflekset (ATNR) & $3 / 7$ & $42 \%$ \\
\hline Tonic Labyrinthine Reflex (TLR) & $2 / 7$ & $28 \%$ \\
\hline Symmetrical Tonic Neck Reflex (STNR) & $2 / 7$ & $28 \%$ \\
\hline Spinal Galant Reflex & $1 / 7$ & $14 \%$ \\
\hline Moro Reflex & $2 / 7$ & $28 \%$ \\
\hline Rooting Reflex & $1 / 7$ & $14 \%$ \\
\hline Suck Reflex & 0 & 0 \\
\hline Palmar Reflex & $1 / 7$ & $14 \%$ \\
\hline
\end{tabular}

7 children who underwent INPP Program, 3 or $42 \%$ of them guarding reflex ATNR and 2 or $28 \%$ guarding reflex TLR, 2 or $28 \%$ STNR guarding reflex, 1 or 14\% of them watched Spinal Galant reflex, 2 or 28 Moro reflex guarding\%, 1 or 14\% of them watched Rooting reflex, reflex Sucking 0 children watched and watched 1 or $14 \%$ Handheld reflex.

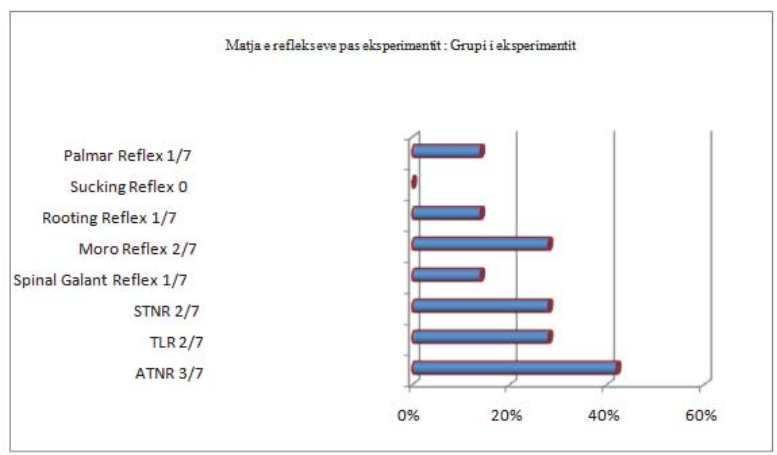

Reflexes measurements after the experiment: control group Initial reflexes with unconstrained Total \%

Asymmetrical Tonic Neck Reflex (ATNR) 6/7 87 \%

7 children who underwent no INPP Program Keeton had after 9 months results: 6 or $87 \%$ of them guarding reflex ATNR and TLR, five children or $71 \%$ of them STNR guarding reflex, 3 children and $42 \%$ of them watched Spinal reflex Galant, 5 or $71 \%$ of them watched the Moro reflex, 2 or $28 \%$ of them watched Rooting reflex, 1 or $14 \%$ guarding reflex Sucking and 2 or $28 \%$ Handheld guarding reflex. 


\section{Conclusions}

As seen from the findings of the study all children who underwent therapy based motor reflex type had a decreased level of unconstrained initial reflexes compared with control children who did not undergo such therapy. Movements, although the children were 6-10 years of age, they managed to reactivate the brain, giving a second chance to be developed. They helped in encouraging the development of neurons-motor skills and academic achievement.

Today there is ample theoretical information, what reflexes their types, their importance in the life of the individual as well as practical information on the movements that should make the baby, the position held as overthrown or backward, motor exercises to help the mothers, you implement them with babies etc. to precede neurological disorders.

\section{Bibliografia}

Barkley, R. A. (1997). Behavioral inhibition, sustained attention, and executive functions: Constructing a unifying theory of ADHD. Psychological Bulletin, 121 (1), 65-94.

Buzan.T. (2003): "Truri i Femijes", Tirane" Max" 15-28.

Goddard, S (2002): "Reflexes, Learning \& Behaviour". Fern Ridge Press.

Goddard (2012) "Assessing Neuromotor Readiness for Learning".

Hannaford, C. (1995). Smart moves: why learning is not all in your head. Virginia: Great Ocean Publishers. 37-64

Hannaford, C. (1995). Smart moves: why learning is not all in your head. Virginia: Great Ocean Publishers. 96-107

Melillo.R. (2009) Disconnected Kids. The groundbreaking Brain Balance Program for children with autism, ADHD, Dyslexia, and Other Neurological Disorder. Introduction Different Symtoms, one Problem. 3-7.

Melillo.R. (2009) Disconnected Kids. The groundbreaking Brain Balance Program for children ëith autism, ADHD, Dyslexia, and Other Neurological Disorder, 108- 182.

Melillo.R. (2009) Disconnected Kids. The groundbreaking Brain Balance Program for children ëith autism, ADHD, Dyslexia, and Other Neurological Disorder, 213-235.

Melillo.R. (2009) Disconnected Kids. The groundbreaking Brain Balance Program for children with autism, ADHD, Dyslexia, and Other Neurological Disorder. Primitive reflexes, 108.

Middleton, Frank A. \& Peter L. Strick. (1994) Anatomic Evidence for Cerebellar and Basal Ganglia Involvement in Higher Cognitive Function. Science, October 21, (vol. 266), 458-461.

Miller,A; Chretien, K, (2007), The Miller Method 191-222

Neil J. Salkind, (2002) Child Development .Transition from Reflex Movement to Voluntary Movement. 279-282

Olsen, Eric. (1994), Fit Kids, Smart Kids - New Research Confirms that Exercise Boots Brainpower. IN: Parents Magazine, pp.33-35

Albalas, Moses, quoted in Dennison, Paul E. \& Gail E. Dennison. Edu - Kinesthetic In-Depth, The Seven Dimensions of Intelligence. Ventura, CA: Education Kinesiology Foundation, 1990.

Gail. E. (1995) The Big Vision Book. Ventura, CA: Edu-Kinesthetics

Reinhard R, (2004) M.D. Color Atlas of Neurology.Reflexes. P. 40.

Reinhard R, (2004) M.D. Color Atlas of Neurology. Voluntary Movements. P.42-45

Roger S, (July, 1973) quoted in E. Eduarts, Brain Mechanism in Movement, Scientific American, 229, 103.

Rohkamm, R. (2004) M.D. Color Atlas of Neurology.Reflexes. P. 240-281.

Walker, S., Pigott, M (1999) Neuro Emotional Technique, Canadian Chiropractor, Volume 4, № 2, 10-14.

Whitebread, D dhe and Coltman, P" (2008) teaching and learning in the early years", 164215.

Wolf, Theta. Alfred Binet. (1973) Chicago: University of Chicago Press. BIRTH. 52-62

Vasta. R, Haith. M, dhe Miller. S, 2004, Psikologjia e femijea, Tirane, UEGEN, fq. 183-194.

Zafeiriou DI. (2004) Primitive reflexes and postural reactions in the neurodevelopmental examination. Pediatr Neurol; 31:1-8.

Zafeiriou DI. (2004) Primitive reflexes and postural reactions in the neurodevelopmental examination. Pediatr Neurol, 52- 78. 
